\title{
UNIVERSUM
}

\section{RETÓRICA O POÉTICA SUBALTERNA A TRAVÉS DE LA RECONFIGURACIÓN DE LA METÁFORA DE LA CASA EN LOS POEMARIOS CAUSAS PERDIDAS Y GÉNERO FEMENINO DE TERESA CALDERÓN}

\section{Subalternal rhetoric or poetic through the reconfiguration or the house metaphor in Teresa Calderon's} poemary Causas perdidas and Género femenino

\section{Paola LizanaMiranda' ${ }^{\text {(D) }}$}

'Universidad de Playa Ancha de Ciencias de la Educación, Departamento Disciplinario de Literatura, Valparaíso, Chile. plizanamas@hotmail.com

\section{RESUMEN}

Esta investigación busca dar cuenta de los significados hegemónicos del pensamiento androcéntrico occidental, considerándolo como territorio de dominio y violencia que establece centros y márgenes a partir de las dualidades jerárquicas que lo configuran. En este sentido planteamos que en la poesía de Teresa Calderón la imagen lárica se nos presenta como una casa cerrada, espacio que alegoriza la ruina claustrofóbica, detritus devenido del sustrato de dominio en que este se funda. Así mismo evidenciamos una reconfiguración de la connotación tradicional de la metáfora de la casa como espacio de resistencia subalterna, donde las hablantes líricas emprenden trayectos de fuga desterritorializantes del espacio logocéntrico-patriarcal, operación de reconfiguración significante que hemos denominado retórica o poética subalterna. En este sentido señalamos que desarrollar el análisis crítico que aquí proponemos significa hacer confluir las dimensiones políticas y estéticas propias de la producción escritural latinoamericana en un contexto neocolonial.

PALABRAS CLAVE: retórica o poética subalterna; metáfora; casa; ruina lárica; modernidad; contramodernidad.

\section{ABSTRACT}

This research seeks to account for the hegemonic meanings of western androcentric thinking, considering it as a territory of dominion and violence that establishes centers and margins based on the hierarchical dualities that shape it. In this sense, we propose that in the poetry of Teresa Calderón the lauric image is presented to us as a closed house, a space that allegorizes claustrophobic ruin, detritus derived from the domain substrate on which it is founded. We also show a reconfiguration of the traditional connotation of the house's metaphor as a space for subaltern resistance, where lyric speakers undertake deterritorializing escape routes of the logocentric-patriarchal space, a significant reconfiguration operation that we have called subaltern rhetoric or poetic. In this sense, we point out that to develop the critical analysis that we propose here means to bring together the political and aesthetic dimensions of Latin American scriptural production in a neo-colonial context.

KEYWORDS: subaltern rhetoric or poetic; metaphor; house; lauric ruin; modernity, countermodernity.

Fecha de Recepción 20I9-10-20

\section{Fecha de Evaluación} 2020-OI-06
Fecha de Aceptación $202 \mathrm{I}-\mathrm{O} 3-3 \mathrm{I}$ 


\section{TERESA CALDERÓN DATOS BIOGRÁFICOS, TEMÁTICA Y ESTILOS DE SUS OBRAS}

\footnotetext{
¿QQué es, entonces, la verdad? Un dinámico tropel de metáforas, metonimias y antropomorfismos; en suma, un conjunto de relaciones humanas que, realzadas, plasmadas y adornadas por la poesía y la retórica, y tras un largo uso, un pueblo considera sólidas, canónicas y obligatorias". (Nietzsche, 2012, 231).
}

Teresa Calderón nació en La Serena en 1955. Es profesora de Castellano y Licenciada en Estética en la Universidad Católica de Chile. En su carrera literaria ha cultivado mayoritariamente la poesía, la narrativa, así como también la docencia y la investigación literaria. Respectos de sus obras se puede destacar la publicación de los poemarios Causas perdidas (1984), Género femenino (1989), Imágenes rotas (1994), No me arrepiento de nada (1999), Aplauso para la memoria (1999), El Poeta y otras Maravillas (2000) y la antología Obra poética (2003) y Elefante (2008). También ha incursionado en la narrativa a través de cuentos como Voces de Eros (1997) y Vida de Perras (2000), y novelas como Amiga mía (2004) y la novela autobiográfica Mi amor por ti (2005). Su producción escritural incluye además exitosos libros para niños como la trilogía Aventuras de Súper Inti y Analfabruja (20II), Súper Inti y el misterio del espejo (2012) y, por último, Súper Inti y Serena atrapados en un portal (2012). Sus publicaciones incluyen también las antologías Veinticinco años de poesía chilena (1996), Esto es el amor: Versos de cien poetas chilenos (200o), La generación N.N o la voz de 8o (2013), todas recopilaciones poéticas desarrolladas en conjunto con su hermana Lila Calderón y su pareja Thomas Harris.

En este artículo abordaremos los primeros dos poemarios publicados por la autora, es decir, Causas pérdidas y Género Femenino, los que creemos nos permitirán dar cuenta en forma acotada de la lectura que nos proponemos a realizar. Cabe señalar que este artículo es parte de una investigación que lleva por nombre Retórica o poética subalterna en la obra de Teresa Calderón a través de la reconfiguración de las metáforas de la casa y del espejo, Tesis para optar al Grado de Doctora en Literatura Hispanoamericana Contemporánea, donde se aborda de forma más amplia el corpus poético y narrativo de la autora.

Pues bien, en relación a este artículo centrado en la poesía, cabe señalar que el profesor Adolfo Bisama plantea que es la faceta lírica donde más destaca esta autora, y es esta la que ha convertido a Calderón en una de las voces más relevantes de las nuevas promociones poéticas chilenas. Para Bisama (2014), la muestra de esta relevancia es el hecho de que en ninguna de las antologías importantes de poesía lírica publicadas en Chile y en el extranjero a partir de los 80 ella está ausente, por ejemplo la de Arteche, Massone y Scarpa, Poesía Chilena Contemporánea; la de Juan Villegas, Nueva poesía femenina Chilena; las de Erwin Díaz, 16 Poetas Chilenos y Desde Parra a Nuestros 
Días; la de Miguel Arteche, Antología de la Poesía Religiosa Chilena; la de ediciones Altazor, Seis Poetas de la República; la de Eugenia Brito, Antología de Poetas Chilenas; entre otras (25I). En este sentido planteamos que su presencia en las antologías más importantes de poesía contemporáneas latinoamericana, así como también las diversas distinciones que ha obtenido (entre ellas, el premio Pablo Neruda en 1992, galardón que se otorga a poetas menores de 40 años y que a Calderón se le otorgó cuando tenía treinta y siete, siendo además, la primera mujer en obtenerlo; el primer lugar en el concurso nacional de poesía El Mercurio en 1988 por su poema "Celos que matan pero no tanto" publicado en Género femenino; el premio Altazor en 1999 por su poemario Elefante; y el premio Nacional de Literatura por su novela Amiga mía el año 2004) demuestran el lugar de preeminencia de la escritora entre las figuras de la llamada generación del 8o, a lo que se suma la traducción de parte de su obra a una multiplicidad de idiomas. Pese a la trayectoría literaria a la que nos hemos referido anteriormente, cabe señalar que en el transcurso de esta investigación fue posible constatar la inexistencia de un corpus crítico que aborde las letras de la autora, razón que creemos justifica la realización del presente artículo. Además, otra de las razones que nos permite justificar la elección del corpus, es la presencia en él de una red simbólica y metafórica, cuyo significado despliega una dimensión política que impulsa la obra de Calderón, ejercicio de resistencia ante la opresión del régimen militar y el patriarcado, dimensión que además creemos supera la contingencia histórica apuntando a visibilizar y desmontar las estructuras simbólicas del dominio occidental. Planteamos también, que además de la dimensión política antes señalada, esta autora desarrolla un componente estético presente en su obra poética. En este sentido tomamos las palabras de Floridor Pérez pertenecientes al prólogo del poemario Causas perdidas (1984), quien señala: "será la eficacia del lenguaje lírico la que brindará profundidad humana y existencial a la poesía de Calderón, lo que la hace destacar entre las voces líricas nacionales" (8). Esta eficacia que enfatiza Pérez creemos le otorga al corpus literario en análisis un valor estético nunca tranzado por la autora. De acuerdo a lo anterior, es de nuestro interés vincular las dimensiones políticas y estéticas presentes en la poesía de la autora bajo la perspectiva que hemos conceptualizado como retórica subalterna. Sin negar que dichas dimensiones sea posible evidenciarlas en la producción de otras escritoras coetáneas, creemos que dado el importante lugar que Calderón ocupa dentro del movimiento escritural posdictadura se torna relevante abordar su obra bajo la perspectiva propuesta ${ }^{\mathrm{I}}$.

\footnotetext{
${ }^{1}$ Respecto de este punto en entrevista con la poeta Alejandra Basualto, perteneciente a la Generación del 8o, señala: "En cuanto a estrategias para sortear la censura, en mi caso, el uso de la metáfora fue un buen resorte". La poeta pone como ejemplo del uso metafórico como estrategia para burlar la censura su poema "Pájaros". (Basualto, citado por Lizana, 2019:217)
} 


\section{RETÓRICA SUBALTERNA}

En el análisis del corpus literario nos proponemos rastrear esa zona de desestabilización de los significados hegemónicos y la emergencia de connotaciones subalternas, operación de desmontaje y reconfiguración que hemos denominado retórica subalterna. Al respecto planteamos que nuestro concepto imbrica múltiples teorías impugnadoras de las totalidades modernas ${ }^{2}$, las que confluyen en el enfoque textual de la realidad social, enfoque bajo el cual los significados socio-culturales son considerados productos de operaciones discursivas plausibles de deconstruir. Además, creemos que emprender un análisis crítico bajo la idea de retórica o poética subalterna significa hacer confluir las dimensiones políticas y estéticas propias de la producción escritural latinoamericana en un contexto neocolonial. Respecto de la primera de dichas dimensiones, planteamos que esta se funda en una larga historia de colonialidad ${ }^{3}$ con sus debidas instancias de negociación, impugnación y resistencia. En relación a la dimensión estética, en el contexto de este análisis, pondremos atención a las metáforas y ese "excedente de sentido" del que habla Paul Ricoeur. Al respecto señalamos que si podemos dar cuenta de cómo dicho excedente abre una zona de desestabilización de los significados hegemónicos, entonces estaremos haciendo funcionar la retórica subalterna. Atendiendo a esto último, cabe precisar que en el contexto de esta investigación abordamos la metáfora a partir de las conceptualizaciones modernas de la misma, según ello, este tropo posibilita la ampliación de los sentidos aceptados a través de la unión de elementos normalmente irreconciliables, poniendo en juego de esta forma la interpretación de elementos opuestos lo que hace surgir nuevas relaciones significantes. Respecto de ello, Ricoeur (1995) señala que la operación metafórica consiste en poner en tensión dos interpretaciones opuestas, dicha operación presupone una interpretación literal que se autodestruye en una contradicción significativa. En este proceso de autodestrucción o transformación, señala Ricoeur, se impone una especie de giro a la palabra, provocando una extensión en el significado a partir de una contradicción, un absurdo o impertinencia semántica (63). Lo anterior pone en cuestión la relación mecánica a través de la cual la tradición explica la operación retórica, es decir, el desplazamiento de significado mediado por

\footnotetext{
2 Para ver más al respecto consultar Retórica o poética subalterna en la obra de Teresa Calderón a través de la reconfiguración de las metáforas de la casa y del espejo (Lizana, 2019:28-58).

3 Respecto de esto, Quijano (1992), señala que colonialismo y colonialidad son conceptos distintos, aunque íntimamente relacionados. El primero de ellos da cuenta de la dominación política, social y cultural directa de los europeos sobre los conquistados de todos los continentes; la colonialidad sería entonces un patrón de poder más profundo y duradero, pero engendrado por el primero. El autor plantea que el colonialismo es, obviamente, más antiguo, en tanto que la colonialidad ha probado en los últimos quinientos años, ser más profunda y duradera que el colonialismo. Pero sin duda fue engendrada dentro de este y, más aún, sin él no habría podido ser impuesta en la intersubjetividad del mundo, de modo enraizado y prolongado (285).

${ }_{4}^{4}$ Entenderemos como excedente de sentido como el desborde de las denotaciones del signo lingüístico y los significados semánticos (Ricoeur, 1995:58).
} 
una relación de semejanza, contrario a ello, la concepción contemporánea pone en juego la interpretación de elementos opuestos lo que hace surgir una nueva relación de sentido, al respecto Ricoeur (1995) señala que dicha operación implica:

...un error calculado, que reúne cosas que no van juntas y que, por medio de este aparente malentendido, hace que brote una nueva relación de sentido, no observada hasta ese momento, entre dos términos que sistemas de clasificación habían ignorado o no habían permitido (64).

Según lo antes planteado, la metáfora implica una ampliación de los sentidos aceptados a través de la unión de elementos normalmente irreconciliables, y de este modo hace surgir una innovación semántica que no tiene reconocimiento en el lenguaje. Es en este sentido que entendemos la operación metafórica como una ruptura de la linealidad del lenguaje, que funciona por un principio de reconciliación de oposiciones i-lógicas permitiendo la emergencia de un sentido no literal y si se quiere subversivo. Planteamos entonces que las significaciones excluidas en la enunciación egológica pueden irrumpir a través del espacio desrregulado de la metáfora, emergiendo con ello significados otros, disonantes y anti-canónicos. Para el análisis específico del corpus poético en torno al cual se desarrolla esta investigación nos centraremos en la metáfora de la casa.

\section{LA CASA: TERRITORIO DE DOMINIO Y RESISTENCIA SUBALTERNA}

En primer lugar, se hace necesario referir brevemente a las significaciones canónicas de la imagen lárica, la que tradicionalmente queda asociada a los términos del hogar y la familia, además, por un desplazamiento de sentido adquiere el significado de protección, amparo, refugio y pertenencia. Respecto de ello, Bachelard (1957), indica que la casa es el símbolo imperecedero de protección y orden. El autor, agrega, que esta posee las connotaciones de alimento/protección y que por extensión se asocia a los orígenes y al vientre materno (I4). Al hacer manifiesta la relación con lo materno Bachelard vincula dicha imagen a lo femenino. En relación a esto podemos señalar que en el plano histórico la unión casa-mujer es de larga data y, en retrospectiva, se puede situar en el inicio de la cultura occidental. En este sentido es posible precisar que para los griegos la mujer estaba consagrada a las tareas domésticas, constituyéndose así en la reina del hogar; de este modo el lar se nos presenta como un espacio inminentemente femenino, espacio cerrado que de acuerdo con Lucía Guerra "anula la contingencia de un afuera, y que en el mundo griego estaba representado por la figura de Hestia: la diosa que residía en el centro de la casa donde cuidaba del fuego y 
resguardaba la inmutabilidad y la permanencia" (2008:I23)5. La casa se configura entonces como un espacio de preservación del orden donde se anula la anarquía que supone lo extraño, por lo mismo va a referir también a las instituciones normativas de la sociedad como la Nación, el Estado, la familia, el matrimonio, etcétera. Miguel Ángel Náter (2007), en tanto, señala que si bien “...bajo una connotación positiva esta metáfora representa los espacios de resguardo, en un sentido negativo se configura un espacio asfixiante o agresor" (275). Es decir, bajo esta última acepción, se puede presentar como un espacio claustrofóbico que alude siempre a estructuras sociales, políticas y/o económicas opresivas, desplegando con ello también su valor subalterno, en tanto espacio de sumisión, pero también de resistencia del poder hegemónico. Conforme a lo anterior, Lucía Guerra (2008), plantea que una de las reivindicaciones de la escritura producida por mujeres ha sido desmitificar el espacio privado de la casa y con ello las relaciones de poder que se dan en su interior:

...en la narrativa producida por mujeres el carácter idílico del espacio familiar de la visión androcéntrica se convierte en espacio restrictivo y de clausura, pero además, dentro de este espacio restringido se filtran intersticios-prácticas de la mujer que transgreden tanto el patriarcado como la praxis caseras que se supone fija e invariable en su repetición y rutina, en su destierro a una posición estática (I26).

Ahora bien, considerando los dichos de Guerra respecto a las posibilidades de introducir transgresiones en la visión lárica tradicional-androcéntrica, en este análisis hiperbolizaremos los alcances metafóricos de la casa hasta hacerla connotar la cultura de occidente en su totalidad. Respecto de lo anterior, hemos considerado los planteamientos de Gilles Deleuze y Felix Guattari (I988), quienes refieren a la casa como una configuración no preexistente y para que cuya existencia sea posible se ha debido trazar un círculo alrededor del centro frágil e incierto, organizar un espacio limitado, a fin de mantener el caos fuera de ella en la medida de lo posible (318). De acuerdo con los autores, la casa corresponde al territorio del orden que establece un centro y líneas divisorias entre un adentro y un afuera. Como bien es sabido, estos pensadores en su obra Mil mesetas. Capitalismo y esquizofrenia, relacionan esta imagen con el concepto de ritornelo, definiendo a este último como "el esbozo de un centro estable y tranquilo, estabilizante y tranquilizante, en el seno del caos" (318) ${ }^{6}$. Planteamos que con lo anterior Deleuze y Guattari otorgan alcances

\footnotetext{
5 La autora señala además que para el mundo antiguo la casa funciona como metáfora de la Nación, así como también como espacio simbólico a través del cual se fijan los roles genéricos de la civitas griega. En este sentido Guerra (2008:I23) contrapone a la figura de Hestia como guardiana de lo inmutable a la de Hermes mensajero y eterno viajero que simboliza la apertura y la movilidad.

${ }^{6}$ Con la relación casa y ritornelo, Deleuze y Guattari (I988) hacen referencia a todo gesto, acto, espacio, visión, etcétera, preservador del caos que siempre conlleva una territorialización o agenciamiento en una estructura de poder (317-358). Respecto del ritornelo, Zourabichvili (2007:9o) señala que este "va hacia el agenciamiento territorial, allí se instala o de ahí sale. En un sentido general, se llama ritornelo a todo conjunto de materias de expresión que traza un territorio, y que se desarrolla en motivos territoriales, en paisajes territoriales (hay ritornelos motrices, gestuales, ópticos, etc.)".
} 
culturales, sociales y epistemológicos a la metáfora del hogar en tanto se entiende como territorio protegido que establece un centro y líneas divisorias entre un adentro y un afuera.

\section{LA CASA CERRADA: ESPACIO DE RUINA CLAUSTROFÓBICA}

Considerando lo señalado, afirmamos que el territorio epistémico de occidente se nos presenta como el espacio ordenado por medio de una voluntad de poder o dominio sobre las fuerzas instintivas, la naturaleza y otras subjetividades. Territorio que establece fronteras divisorias respecto de un afuera constituido por las potencias imaginativas e intuitivas, consideradas inferiores o erróneas. Decimos además, que los cimientos de esta "casa ordenada" fueron edificados en la antigüedad, aunque como bien señala Rosi Braidotti (2015:9I), dicha edificación predominó durante los siglos XVIII y XIX con reinterpretaciones de las ideas clásicas y de los ideales del Renacimiento italiano. Según esto último, creemos que en las obras que compone el corpus de Teresa Calderón que aquí analizamos, este territorio se configura como espacio claustrofóbico y en ruinas, lugar desde donde la hablante y las protagonistas femeninas buscan activamente emprender la fuga desterritorializante. Tal como es posible apreciar en el poema "Paisaje doméstico" perteneciente al poemario Causas perdidas:

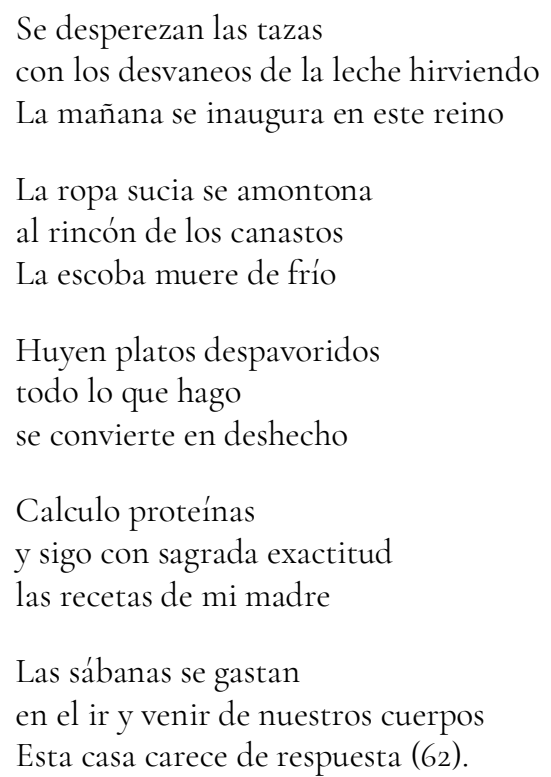

Para desarrollar un análisis de los versos anteriores creemos necesario considerar los planteamientos de Deleuze (1998:6r-62) en su análisis de la obra de Nietzsche, referido a la idea de lo verdadero para la tradición filosófica de occidente. Dicha idea, de acuerdo a los planteamientos nietzscheanos, se fundaría en fuerzas inferiores que se definen como reactivas, debido a que aseguran las tareas de conservación, adaptación y de utilidad, además de situarse en contrario a las 
fuerzas activas que tienen un comportamiento espontáneo e incesantemente toma nuevas direcciones ${ }^{7}$. Conforme a ello, planteamos que en la imagen lárica del poema de Calderón antes citado, la casa se nos presenta como poblada de objetos inertes, donde la ropa sucia se amontona en un rincón, dando cuenta del abandono del espacio doméstico que, al menos en los primeros versos, parece deshabitado. Dentro del poema también, por medio del recurso de la personificación, los objetos cobran vida, aunque sea en un sentido negativo, así nos encontramos con que "la escoba se muere de frío y los platos huyen despavoridos". Pensamos que las anteriores imágenes, tanto las que dan cuenta de la presencia de los objetos inertes, como aquellas en que se los anima para negar la vitalidad de dicho espacio, nos permiten configurar la casa como territorio androcéntrico occidental. Conforme a ello, este se presenta como lugar sitiado, en tanto, se ordena y jerarquiza a partir de oposiciones duales que establecen exclusiones y alteridades. Es por ello que una hablante femenina, la cual aparece como solitaria habitante del mundo doméstico, da cuenta de su confinamiento diciendo "todo lo que hago/se convierte en desecho". En dicho lamento creemos se evidencia lo que ha significado para la mujer —en su condición de otredad— su histórica reclusión en el hogar. Respecto de esto, Simone de Beauvoir (2013), señala que las faenas domésticas a las que se la ha consagrado condenan a la mujer a la inmanencia y repetición; son faenas que se reproducen día tras día, bajo una forma idéntica que se perpetúa casi sin cambios siglo tras siglo, sin producir nada nuevo (65). De allí la intrascendencia de su labor que expresa la voz lírica y que se reitera en la cuarta estrofa del poema de Calderón.

En dichos versos creemos ver una irónica alusión al mundo de la ciencia y de la religión, en tanto la voz lírica declara "calcular proteínas" y seguir con "sagrada exactitud la receta de la madre". Proclamándose de este modo, en una especie de científica y/o sacerdotisa del pequeño e intrascendente mundo de la cocina familiar, invisible y sin prestigio alguno. De acuerdo con ello, es posible afirmar que el confinamiento doméstico femenino le ha significado a la mujer por una parte aislamiento, tal como expresa la solitaria hablante del poema, la cual transita en medio de objetos diversos y, por otra, la condena a detentar las fuerzas reactivas, preservadoras y reproductoras de la vida y del orden social, privándosela de las potencias activas, creativas, que implican riesgo y encierran la posibilidad de prestigio y la trascendencia ${ }^{8}$. Con lo anterior, sostenemos que se pone

\footnotetext{
7 Sobre las fuerzas reactivas, Nietzsche (2002) las califica como una moral del esclavo, las que se otorgan como consuelo a aquellos seres a los cuales está vedada la auténtica reacción, la reacción de la acción. Para el filósofo alemán la promesa de la vida eterna es una compensación de los débiles para resarcirse de las penurias terrenas en la fe, en el amor y en la esperanza. Además, plantea que el sentido de toda cultura y de toda moral religiosa es la crianza de un hombre manso y civilizado, un animal doméstico (II-I6).

${ }^{8}$ Respecto de esta exclusión histórica, De Beauvoir (2013) plantea la peor maldición que pesa sobre las mujeres es hallarse excluidas de las expediciones guerreras; en tanto, no es dando la vida, sino arriesgándola como el hombre se eleva sobre el animal, por ello en la Humanidad se acuerda la superioridad, no al sexo que engendra, sino al que mata (66).
} 
en relación la ideología patriarcal, la jerarquización del espacio y la conquista de la condición ontológica, ya que en lo público-masculino radica la trascendencia y el prestigio, en tanto que el ámbito de lo privado-femenino se presenta como complemento insignificante, lugar de inmanencia y repetición. Lo anterior, tiene profundas implicancias en tanto el pensamiento dual y jerárquico establece límites y exclusiones materiales y discursivas que configuran los sujetos?

Ahora bien, volviendo al poema citado en la última estrofa, la ruina del espacio doméstico se presenta a través de las "sábanas que se gastan en el ir y venir de los cuerpos", aludiendo sin duda al amor físico, como a la rutina conyugal. En términos más amplios, mediante las sábanas gastadas, así como con la totalidad del abandono que configura el espacio lárico en el poema, Teresa Calderón da cuenta de una crisis epistemológica de grandes alcances. Respecto de dicha crisis, Rosi Braidotti (2015), señala que "la muerte de Dios" declarada por Nietzsche implica el fin de la estabilidad metafísica y la validez universal del sujeto humanístico europeo, y con ello el advenimiento del pensamiento crítico poshumanista y la incerteza ontológica (I4). La conciencia crítica que ha devenido en la ruina o al menos en el deterioro de la idea del ser fundado en la razón, creemos, diferencia a occidente de otras sociedades patriarcales, convirtiendo el territorio epistémico en un lugar plagado de incertezas o, en palabras de la hablante, en una casa que carece de respuesta, como se expresa en el verso final del poema antes citado.

Conforme a lo antes señalado, planteamos que la devastación lárica en el corpus alegoriza los escombros de las nociones ordenadoras de occidente, es decir las certezas de lo verdadero y/o trascendente del dogma científico, filosófico y religioso. En este sentido señalamos que el espacio poético está poblado de escombros, como se puede ejemplificar a través "Hazañas de la memoria" perteneciente al poemario Causas pérdidas, donde la ruina se configura como "una casa/que cerró sus puertas" y que "Se fue / Muriendo / en el nombre / y gracia de la mismísima / vida" (40). En lo anterior, creemos ver poetizado el debilitamiento de los instintos de vida derivados de las restricciones logocéntricas, que como ya antes indicamos, establece exclusiones y jerarquías, clausurando las potencias activas en beneficio de las fuerzas reactivas de preservación y orden.

De acuerdo a lo antes señalado, creemos evidenciar que dicho encierro claustrofóbico denota las clausuras impuestas por el pensamiento dual jerárquico del humanismo occidental. En este sentido planteamos que el espacio poético de Género femenino se nos presenta como un espacio sitiado, encierro metaforizado a través de la referencia epigramática que nos introduce en el

9 Respecto de ello Judith Butler (rg93) señala que "En este sentido, pues, el sujeto se constituye a través de la fuerza de la exclusión y la abyección, una fuerza que produce un exterior constitutivo del sujeto, un exterior abyecto que después de todo, es 'interior' al sujeto como su propio repudio fundacional” (20). 
territorio asfixiante de violencia patriarcal: "Ai / EN CASA / CERRADA NO / ENTRAN / MOSCAS" (I3). Planteamos que dicho título, que describe el dibujo de una casa, funciona como puerta de entrada en el espacio androcéntrico que una voz poética femenina busca impugnar, tal como ocurre en el poema "Ser mujer":

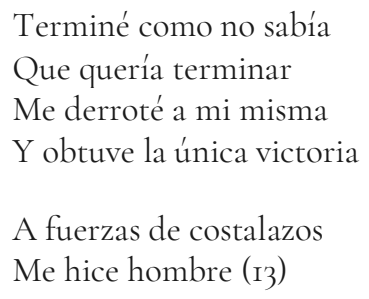

En el poema citado se expresa una intención de refutar la validez de lo masculino como categoría universal, así como la intención de visibilizar esa universalidad hegemónica donde, por contraposición, lo femenino deviene en inesencial, "Yo soy una / y una no es ninguna" (85), dirá casi al final del poemario la voz lírica, volviendo a contraatacar el lugar de superioridad del sujeto universal. En este sentido afirmamos que el espacio poético se nos presenta como una "casa cerrada" cuya clausura proviene de la imposibilidad de desprenderse de la oposición dual hombre/mujer que, pese a impugnarla, sigue operando bajo sus coordenadas epistemológicas sin encontrar la salida de ellas. Al respecto Deleuze (1996:5) señala que la desestabilización de dichas categorías radica en un devenir minoritario desbordantes de las concepciones y expresiones dominantes; agregando que el devenir no funciona en el otro sentido y no se deviene en hombre, dado que el hombre se presenta como una expresión dominante en tanto el devenir mujer, animal o molécula, contiene siempre un componente de fuga que se sustrae de su propia formalización.

En este sentido, decimos que la voz poética denuncia y visibiliza lo masculino como categoría universal, pero parece no encontrar una puerta de salida de esa casa cerrada ya que plantea devenir en hombre, es decir, invertir las categorías o apropiarse de la masculinidad con todo su prestigio simbólico como única victoria posible. De acuerdo a ello, la afirmación de la hablante "me hice hombre" aunque encierra un acto de resistencia, sigue operando bajo la lógica dual del episteme occidental, en tanto que para encontrar una salida se precisa establecer líneas de fuga o flujos desbordante de las dicotomías fundantes. Ahora bien, en la casa territorializada que habita la voz lírica, esta actitud de impugnación al logocentrismo frecuentemente se escenifica en el ámbito de lo doméstico y dentro de las dinámicas relacionales de la familia y el matrimonio, como acontece en el poema "A diez round" de Causas perdidas, en el cual, lejos de sus connotaciones idílicas, el espacio lárico se presenta como lugar de enfrentamiento y violencia: 
En este rincón, mano de piedra,

peso completo

o sea tú queridito,

poseedor de la verdad,

dispuesto a ceñirte la corona

para siempre

En este otro rincón,

la dolorida

amiga predilecta del silencio,

señora de las causas perdidas,

empecinada en dar la lucha hasta la muerte,

amorcito.

Se inicia el combate [...]

Una que no soy yo ha tirado la toalla,

porque tú, mano y corazón de piedra,

me despedazas

en nuestro ring con ventanas a la calle (64-65)

En la cita anterior, es posible evidenciar la inversión de la tradicional connotación de la casa como lugar de orden y amparo al de un espacio de agresividad, con ello las relaciones familiares se presentan como intercambio hostil, en tanto que el territorio de protección se trastoca en cuadrilátero o "ring con ventanas a la calle". Conforme a ello, decimos que es posible interpretar este poema a partir la interpelación a las dinámicas de violencia patriarcal. Ahora bien, bajo nuestra lectura, la que amplifica los alcances connotativos de la metáfora de la casa, creemos evidenciar que el enfrentamiento enunciado no solo queda circunscrito al ámbito doméstico y las relaciones maritales, sino que se proyecta hiperbólicamente a toda la cultura occidental y el sustrato de dominio en que esta se funda. Respecto de lo anterior, creemos ver la explicitación dentro del espacio poético de la oposición dual sujeto/objeto, donde la primera de estas categorías corresponde al sujeto androcéntrico y racional, tal como se establece en la presentación del primer contendor que se describe como poseedor de la verdad y como dispuesto a ceñirse la corona para siempre. Decimos entonces que este luchador - el sujeto de la tradición humanista- se nos presenta a partir de sus históricos atributos: racionalidad y dominio. En tanto, la segunda contrincante se caracteriza a sí misma como "la dolorida, amiga predilecta del silencio y señora de las causas perdidas", dando cuenta de su histórica desventaja.

Según lo planteado, decimos que los versos citados escenifican la relación dialéctica de las categorías dicotómicas sujeto/objeto que, tal como explicita la filosofía hegeliana, es una lucha a muerte entre dos seres por prestigio y reconocimiento - el amo y el esclavo- donde el primero será aquel que logre suprimir "dialécticamente" a su oponente. Es decir, debe dejarle la vida y la conciencia y destruir solo su autonomía, dicho de otra manera, debe someterlo (Kojéve, 1982:5-7). 
Hacia el final del poema el resultado es adverso para la hablante, así lo manifiesta cuando declara "Una que no soy yo ha tirado la toalla", dando cuenta a través de esta coloquial expresión de la derrota que ha situado a la mujer como alteridad histórica, objeto inesencial o esclavo a decir de Hege $^{10}{ }^{\text {. }}$. Conforme a lo antes planteado, señalamos que el espacio poético aún se nos presenta como una "casa cerrada", cuya clausura proviene de la imposibilidad de desprenderse de las oposiciones dialécticas hombre/mujer, sujeto/objeto, masculino/femenino, dentro/fuera, entre otras. Pese a "pelear" contra ellas, la voz poética sigue deambulando bajo sus coordenadas sin encontrar la salida.

\section{DE LA CASA PARA AFUERA: FUGA DESTERRITORIALIZANTE DE LAS CLAUSURAS EPISTÉMICAS}

Conforme a lo antes planteado, nos es posible relacionar semánticamente las instituciones autoritarias y patriarcales como la familia, el matrimonio y la dictadura, con la alegorización del territorio devastado y clausurado del pensamiento moderno-occidental. En este sentido, planteamos que dentro del espacio poético y narrativo emerge la voz subalterna que consciente de su condición traza líneas de fugas, a veces irónicas, como ocurre en Género femenino a través del breve poema "Estrategia" donde se plantea "Mujer que arranca del marido sirve para otra guerra" (79). En otras ocasiones, en el mismo poemario dicha fuga se presenta como un plan sin concretar: "Planeo una fuga / salgo de escena" (31). En tanto en otras, la voz subalterna deviene en intensidades puras, donde se deshacen todas las formas en una materia no formada que es flujo desterritorializante (Deleuzze y Guatarri, 1975:24), tal como ocurre en el poema "Autor-retrato" también perteneciente a Género femenino:

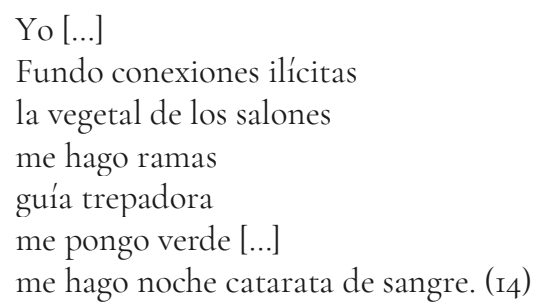

En los versos anteriores se configura un "yo" móvil que es flujo e intensidad a partir del devenir vegetal-rama-trepadora-cascada de sangre. Con lo anterior planteamos que la voz lírica abre un espacio de salida o, en palabras de Deleuze, se desterritorializa del espacio cerrado de la casa metáfora del episteme-hegemónico-occidental, y como queda gráficamente establecido en el

\footnotetext{
1o Respecto de la condición de esclavo Kojéve, refiriendo a los planteamientos de Hegel, señala que este sigue siendo todavía un ser "inmediato", natural, "bestial". En tanto el amo por su lucha ya es humano. Y su comportamiento es, por tanto, igualmente "mediatizado" o humano, tanto frente a las cosas como ante los otros hombres, que en última instancia son esclavos para él (I982:9).
} 
epigrama que inaugura la segunda parte del poemario Género femenino en este devenir empieza a habitar los espacios "De la casa para afuera" (I8). De acuerdo a lo antes señalado, planteamos que dentro del corpus la casa se nos presenta como un territorio que en su acepción de casa cerrada metaforiza la ruina epistémica occidental, así como también, el encierro claustrofóbico de la sociedad patriarcal y la dictadura militar. En ese territorio sitiado la hablante lírica establece estrategias de aceptación y negociación de dichas clausuras, aunque estratégicamente además logra hacer emerger una subjetividad que desbordas las categorías identitarias unívocas, deviniendo vegetal e inorgánica. Este devenir se presenta también como desplazamiento subrepticio que logra encontrar una salida de la edificación logocéntrica, tal como se manifiesta en el poema "Haría falta" de Género femenino: "y los ojos subterráneos diseñaran caminos / o el silencio se deslizará despacito por las secretas fisuras de la casa" (I9). En ello creemos ver, además de una fuga desterritorializante propuesta como deslizamiento por las fisuras de la casa, la exhortación al surgimiento de una visión iconoclasta de la subjetividad femenina, metaforizada a través de "ojos subterráneos". Conforme a lo anterior señalamos que en el espacio del corpus analizado en este artículo, es posible evidenciar la reconfiguración de la connotación tradicional de la casa como lugar de orden y protección hacia su significación subalterna, esto es como fuga desterritorializante de la ruina claustrofóbica del episteme occidental.

\section{CONCLUSIONES}

En el presente trabajo se han abordado los poemarios Causas perdidas y Género femenino de Teresa Calderón bajo la idea de retórica o poética subalterna. Entendiendo lo anterior como el desmontaje de significados hegemónicos y la posterior reconfiguración en significaciones otras, ilógicas y subalternas. Conforme a ello nos hemos propuesto hacer confluir las dimensiones estéticas y políticas, ampliando y profundizando el análisis de sus letras, las cuales (como damos cuenta en esta investigación) han sido omitidas desde el punto de vista crítico, razón por la que nos parece relevante el desarrollo del presente artículo. Cabe señalar que en este análisis nos hemos centrado en reconfiguración significante de la metáfora de la casa.

Pues bien, como parte de la elaboración de este artículo se ha operacionalizado teóricamente el concepto de retórica o poética subalterna, precisando que la operación metafórica, bajo las concepciones contemporáneas, se nos presenta como un error calculado que reúne cosas que no van juntas y que, por medio de este aparente malentendido, hace que brote una nueva relación de sentido. Es esta última consideración la que nos ha llevado a concebir este análisis como 
ampliación de los sentidos tradicionales o canónicos hacia connotaciones subalternas de la metáfora de la casa.

Respecto de esto último cabe señalar que hemos considerando las posibilidades de introducir transgresiones en la visión lárica tradicional-androcéntrica y las relaciones de poder que se dan en su interior. En este sentido, se ha hiperbolizado los alcances de la metáfora de la casa hasta hacerla connotar la cultura de occidente en su totalidad, conforme a lo cual dentro del corpus la imagen de la casa cerrada se nos presenta como el territorio sitiado y en ruinas de los fundamentos epistémicos occidentales. Lo anterior nos ha permitido concluir que en los poemarios Causas perdidas y Género femenino bajo la imagen de "casa cerrada", el territorio del pensamiento de la tradición humanista se nos presenta como ruina claustrofóbica, devastación devenida del sustrato de dominio en que este se funda, el cual queda configurado como espacio de violencia y dominación patriarcal y neocolonial. Así mismo, en los poemarios analizados, la imagen de la "casa para afuera" da cuenta de la fuga desterritorializante emprendida por las hablantes líricas de las clausuras dicotómicas del pensamiento occidental, en búsqueda de nuevas figuraciones de subjetividad.

Conforme a lo antes planteado, afirmamos que en la obra de Teresa Calderón es posible evidenciar el desmontaje de significados hegemónico y la reconfiguración de significaciones subalternas de la metáfora de la casa.

Desde el punto de vista de las proyecciones de esta investigación creemos es posible desarrollar la lectura aquí presentada en un corpus más amplio, que abarque la obra poética y narrativa de la autora, análisis realizado en la tesis para optar al Grado de Doctora en Literatura Hispanoamericana Contemporánea, Retórica o poética subalterna en la obra de Teresa Calderón a través de la reconfiguración de las metáforas de la casa y del espejo, donde se aborda gran parte de la producción literaria de la autora, pudiéndose constatar en ella la presencia de una compleja red simbólica que otorga coherencia a las letras de Calderón.

Así mismo, creemos, sería de gran interés llevar a cabo el mismo análisis exegético en obras producidas por otros autores que compartan características escriturales con Teresa Calderón, en tanto como hemos evidenciado a través de nuestra investigación, el gesto político de textualizar la diferencia sexual fue propio de las letras producidas por las autoras de la generación a la que pertenece la escritora, las que no solo retomaron el acto de resistencia feminista abruptamente interrumpido por el quiebre democrático de 1973 , sino que además marcaron el rumbo de la 
literatura hasta la actualidad. Por ello afirmamos, que en muchas de las congéneres de Calderón, así como también en escritoras más recientes, es posible observar la misma labor desbordante de los sentidos unívocos donde lo femenino se presenta como signo desregulador del logos, logrando movilizar las asociaciones significantes hegemónicas. Lo anterior, pensamos, posibilita trasladar este análisis a las letras de otras narradoras y poetas nacionales bajo la idea de retórica subalterna aquí desarrollada.

Por otra parte, cabe resaltar que la escritura latinoamericana nunca ha podido del todo renunciar a su vocación política, debido a su larga historia de subyugación colonial. Dicha vocación ha sido acompañada además por experimentaciones e innovaciones estéticas. Lo anterior, pensamos, demanda una crítica que haga confluir los aspectos políticos y estéticos presentes en gran parte de la producción poético-narrativa contemporánea. Esto último ofrece un amplio horizonte de estudio ya sea centrado en la metáfora o en otras figuras retóricas pertenecientes a la producción escritural del continente bajo el concepto exegético aquí propuesto. En este sentido planteamos sería de relevancia rastrear en otros textos de la literatura iberoamericana esas zonas de desestabilización de las connotaciones hegemónicas y la reconfiguración de significantes subversivos, operación que hemos denominado retórica subalterna.

\section{RECONOCIMIENTOS}

El presente Trabajo de investigación fue financiado por la Beca Doctorado Nacional 2018, Comisión Nacional de Investigación Científica y Tecnológica (CONICYT).

\section{REFERENCIAS}

Bachelard, G. (1957). La poética del espacio. Buenos Aires: Fondo de Cultura Económica.

Bisama, A. (2014). Celos que matan pero no tanto, poemario de Teresa Calderón estrategias textuales e intertextuales. Recuperado de https://cutt.ly/WmYMGoF

Braidotti, R. (2015). Lo posthumano (Juan Carlos Gentile, trad.). Barcelona: Gedisa. (Obra original publicada en 2013).

Butler, J. (1993). Cuerpos que importan. Sobre los límites materiales y discursivos del sexo (Alcira Bixio, trad.). Buenos Aires: Paidós. (Obra original publicada en 1993).

Calderón, T. (1984). Causas perdidas. Santiago de Chile: Ediciones Artesanales.

Calderón, T. (1989). Género femenino. Santiago de Chile: Planeta Chilena S.A. 
De Beauvoir, S. (2013). El segundo sexo (Juan García Puente, trad.). Buenos Aires: Debolsillo. (Obra original publicada en 1949).

Deleuze, G y Guattari, F. (1975). Kafka por una literatura menor (Jorge Aguilar Mora, trad.). México D.F.: Ediciones Era. (Obra original publicada en 1975).

Deleuze, G y Guattari, F. (1988). Mil mesetas. Capitalismo y esquizofrenia (José Vázquez Pérez, trad.). Valencia: Pre-textos. (Obra original publicada en 1980).

Deleuze, G. (1996). Crítica y clínica (Thomas Kauf, trad.). Barcelona: Anagrama. (Obra original publicada en 1993).

Deleuze, G. (1998). Nietzsche y la filosofía (Carmen Artal, trad.). Barcelona: Anagrama. (Obra original publicada en 1962).

Guerra, L. (2008). Mujer y escritura: fundamentos teóricos de la crítica feminista. Santiago: Cuarto Propio.

Kojeve, A. (1982). La dialéctica del amo y del esclavo en Hegel. Buenos Aires: La Pléyade.

Lizana, P. (2019). Retórica o poética subalterna en la obra de Teresa Calderón a través de la reconfiguración de las metáforas de la casa y del espejo. Tesis para optar al Grado de Doctora en Literatura Hispanoamericana Contemporánea. Universidad de Ciencias de la Educación del Playa Ancha, Valparaíso.

Náter, M.Á. (2007). José Donoso: entre la Esfinge y la Quimera. Santiago de Chile: Cuarto Propio.

Nietzsche, F. (2012). Verdad y mentira en sentido extramoral y otros fragmentos de filosofía. Madrid: Editorial Tecnos. Recuperado de https://cutt.ly/7mYryoP

Nietzsche, F. (2002). La genealogía de la moral: Un escrito polémico. Madrid: Alianza Editorial.

Pérez, F. (1984). Prólogo. En: Teresa Calderón, Causas perdidas, pp.8-9. Santiago de Chile: Ediciones Artesanales.

Quijano, A. (1992). Colonialidad y modernidad/racionalidad. Perú Indígena, vol.r3, №29, p.II-20. Lima: Ministerio de Trabajo y Comunidades. Recuperado de https://cutt.ly/PmYis6g

Ricoeur, P. (1995). Teoría de la interpretación. Discurso y excedente de sentido (Graciela Monges Nicolau, trad.). México D.F: Siglo XXI. (Obra original publicada en 1967).

Zourabichvili, F. (2007). El vocabulario de Deleuze (Víctor Goldstein, trad.). Buenos Aires: Atuel. (Obra original publicada en 2003). 